\title{
Comunicação/Communication
}

\section{Sorotipos virais de dengue identificados em crianças de Manaus, Estado do Amazonas, 2008}

\author{
Dengue virus serotypes in children of Manaus, State of Amazonas, 2008
}

\author{
Cristóvão Alves da Costa ${ }^{1}$ e Grecilane Palheta Façanha ${ }^{2}$
}

\section{RESUMO}

Introdução: A dengue é uma arbovirose que vem causando sérios problemas de saúde pública, em regiões tropicais e subtropicais do planeta. Métodos: Neste estudo, foram investigadas amostras de sangue de crianças, através da RT-PCR, com o intuito de se identificar sorotipos do vírus dengue nessa população infantil, em Manaus/AM, durante o ano de 2008. Resultados: O DENV-3 foi o único sorotipo viral identificado. Conclusões: No presente estudo, $83 \%$ das crianças analisadas apresentaram resultado negativo para dengue através do RT-PCR sugerindo a ocorrência de outras doenças febris que necessitam ser esclarecidas.

Palavras-chaves: Vírus dengue. RT-PCR. Crianças.

\begin{abstract}
Introduction: Dengue is an arbovirus that continues to cause serious public health problems in tropical and sub-tropical regions of the planet. Methods: In this study, blood samples from children were investigated by RT-PCR, aimed at identifying dengue virus serotypes in Manaus, AM, in 2008 in this infant population. Results: DENV-3 was the only serotype identified. Conclusions: In this study, $83 \%$ of children examined were negative for dengue by RT-PCR, suggesting the occurrence of other febrile illnesses that need to be determined.
\end{abstract}

Keywords: Dengue virus. RT-PCR. Children.

A dengue é causada por um arbovírus pertencente ao gênero Flavivirus, cujas características antigênicas o diferem em quatro sorotipos distintos: DENV-1, DENV-2, DENV-3 e DENV-4 ${ }^{1}$.O DENV pode apresentar tanto infecções assintomáticas quanto quadro graves fatais ${ }^{2}$. Nas Américas, seu principal mosquito vetor é o Aedes aegypti $i^{3}$.

Apesar de na América Latina a forma grave ser prevalente em adultos $^{4}$, nos últimos dois anos, no Brasil, tem sido observada uma mudança nos padrões etários para a ocorrência de febre hemorrágica do dengue (FHD). Em Manaus, capital do Amazonas, o mesmo comportamento foi observado por Rocha e Tauil ${ }^{5}$, em 2006 e 2007. O deslocamento para faixas etárias mais jovens também assinala a gravidade da situação, já que as crianças são mais susceptíveis ao extravasamento plasmático, por apresentarem permeabilidade vascular aumentada ${ }^{4}$. Esse agravante, associado à alta endemicidade e a cocirculação dos três sorotipos (DENV-1, DENV-2 e DENV-3) no país, mostra um importante fator de risco para o desenvolvimento

1.Laboratório de Virologia Tropical, Coordenação de Pesquisas em Ciências da Saúde, Instituto Nacional de Pesquisas da Amazônia, Manaus, AM. 2. Programa de PósGraduação em Medicina Tropical, Universidade Federal do Amazonas, Manaus, AM. Endereço para correspondência: Dr. Cristóvão Alves da Costa. Laboratório de Virologia Tropical/CPCS/INPA. Av. André Araújo 2936, Aleixo, 60060-001 Manaus, AM. Tel: 5592 3643-3288; Fax: 5592 3643-3091

e-mail: crvcosta@inpa.gov.br

Recebido para publicação em 08/04/2010

Aceito em 16/09/2010 de FHD e síndrome do choque do dengue (SCD), principalmente por causa da introdução de novos genótipos virulentos.

Neste estudo, objetivou-se investigar os sorotipos do vírus dengue em crianças de 0 a 10 anos, no município de Manaus, Amazonas e estabelecer através da técnica de RT-PCR os sorotipos virais infectantes circulantes na Cidade de Manaus, bem como apresentar aspectos epidemiológicos da ocorrência do vírus dengue na população infantil.

Participaram do estudo 94 amostras de crianças com suspeita de dengue, na faixa etária de 0 a 10 anos de idade, de ambos os sexos, cujas amostras de sangue total e/ou soro, coletadas até 5 dias após o início dos sintomas (período de viremia), foram encaminhadas ao Laboratório Central de Saúde Pública do Amazonas, da Fundação de Vigilância em Saúde (LACEN-AM/FVS) para isolamento viral. As variáveis analisadas foram: idade, sexo, bairro de residência, zona de residência, data de início dos sintomas e sorotipo viral infectante. As informações foram retiradas das fichas de investigação laboratorial.

O método de identificação do RNA viral do dengue foi feito através da reação em cadeia da polimerase pela transcriptase reversa (RT-PCR), seguida por um semi-nested-PCR, segundo metodologia descrita por Lanciotti cols ${ }^{6}$. Os primers específicos usados no presente trabalho tiveram como região alvo a confluência dos genes $\mathrm{C} / \mathrm{prM}^{6}$.

A extração do ácido ribonucléico (RNA) foi executada utilizando-se o método do Trizol LS Reagent (Invitrogen, São Paulo, Brasil), de acordo com as especificações do fabricante. Os produtos da amplificação foram submetidos à eletroforese em gel de agarose $2 \%$ em tampão Tris-Borato-EDTA pH 8,3, utilizando-se um padrão de 100 pares de bases, corados com brometo de etídeo $1 \%$ e visualizados por meio de transluminador de luz ultravioleta.

O software utilizado na análise estatística foi o programa Epi-Info versão 3.5.1 para Windows. Na análise dos dados categorizados, foi utilizado o teste do qui-quadrado de Person e para a comparação da média de idade foi utilizada a estatística de $t$ de Student, pois a mesma apresentou distribuição normal $(\mathrm{p}>0,05)$ por meio do teste de Shapiro-Wilk. O nível de significância utilizado nos testes foi de 5\%.

Das 94 amostras analisadas pelo estudo, 16 (17\%) amostras foram positivas para dengue. O DENV-3 foi o único sorotipo viral do dengue encontrado neste estudo.

Dentre os casos positivos, $62,5 \%$ foram do sexo masculino e $37,5 \%$ do sexo feminino. Porém, conforme descrito na Tabela 1, não foi encontrada associação estatisticamente significante do resultado da RT-PCR, em relação ao sexo $(p=0,315)$. A média e o desvio padrão da idade das crianças com RT-PCR positivo e negativo foi respectivamente 6,4 $\pm 3,2$ e 5,5 $\pm 2,7$ (Tabela 1 ). Também, não foi constatada diferença estatística $(\mathrm{p}=0,289)$ ao nível de $5 \%$. O mesmo ocorreu na comparação da idade em relação ao sexo $(p=0,433)$. 
TABELA 1 - Distribuição segundo o resultado da RT-PCR para dengue em crianças de 0 a 10 anos atendidas no LACEN-AM/FVS, durante 0 ano de 2008, segundo o sexo, Manaus-AM.

\begin{tabular}{|c|c|c|c|c|c|c|}
\hline \multirow[b]{3}{*}{ Sexo } & \multicolumn{4}{|c|}{ Resultado da RT-PCR } & & \\
\hline & \multicolumn{2}{|c|}{ positivo } & \multicolumn{2}{|c|}{ negativo } & \multicolumn{2}{|c|}{ Total } \\
\hline & fi & $\overline{\%}$ & fi & $\overline{\%}$ & fi & $\%$ \\
\hline Feminino & 6 & 13,0 & 40 & 87,0 & 46 & 48,9 \\
\hline Masculino & 10 & 20,8 & 38 & 79,2 & 48 & 51,1 \\
\hline$\overline{\text { Total }}$ & 16 & 17,0 & 78 & 83,0 & 94 & 100,0 \\
\hline
\end{tabular}

RT-PCR: reverse transcriptase - polymerase chain reaction, fi: frequência absoluta. $\chi^{2}=1,01, \mathrm{p}=0,315$

Todas as amostras positivas desse estudo pertenceram ao primeiro trimestre de 2008. Os demais meses não apresentaram casos positivos. O tempo médio de diagnóstico (dias de doença), que correspondem aos dias entre a data do início dos sintomas e data da coleta da amostra de sangue da criança foi de 2,8 dias $(\mathrm{Dp} \pm 0,98)$, conforme pode ser visualizado na Figura 1.

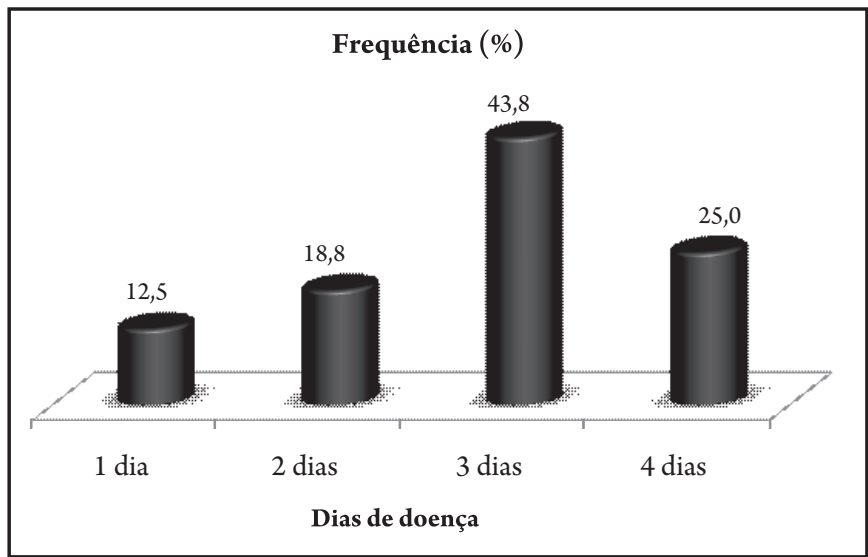

FIGURA 1 - Casos de dengue diagnosticados pelo RT-PCR, entre as crianças de 0 a 10 anos, atendidas no LACEN-AM/FVS, segundo dias de doença. Manaus-AM, 2008.

Quanto à distribuição espacial dos casos positivos para DENV-3, por bairros e zonas da Cidade de Manaus, em ordem decrescente, destacaram-se: Alvorada (18,7\%), Compensa e São José Operário (12,5\% cada). Juntos, estes três bairros somaram 43,7\% dos casos. Todas as zonas do município de Manaus apresentaram crianças positivas nesse estudo, sendo que a zona sul foi responsável pelo maior número de casos, alcançando $25 \%$, zonas oeste e centro-oeste ( $18,8 \%$ cada). Zonas centro-sul e norte mostraram os menores índices, com 6,3\% dos casos, cada uma.

Neste estudo, foram avaliadas 94 amostras de crianças, encaminhadas ao LACEN-AM/FVS, durante o ano de 2008, no qual se verificou uma prevalência de $17 \%$ para o $\mathrm{DENV}$, todos pertencentes ao sorotipo DENV-3. Em Manaus, durante o ano de 2002, o DENV-3 foi isolado pela primeira vez e ocasionou uma epidemia no primeiro quadrimestre de 2008. Segundo dados da Secretaria de Vigilância em Saúde ${ }^{7}$ o DENV-3 foi confirmado em $96,6 \%$ dos casos onde houve isolamento do vírus no Estado do Amazonas, confirmando os achados deste estudo.

Em Manaus, num estudo clínico-epidemiológico em crianças menores de 15 anos, acometidas por dengue autóctone, no período de 2006 e 2007, relatou-se também a prevalência do DENV-35. Houve prevalência absoluta do DENV-3, o que não significa que os outros sorotipos não estivessem presentes. O DENV-3 foi o último sorotipo introduzido em Manaus e parte da população já possui imunidade contra os sorotipos DENV-1 e DENV-2, que provocaram duas principais epidemias em 1998-1999 e 2000-2001. A introdução do DENV-3 encontrou uma população completamente susceptível, principalmente a infantil, que talvez tenha contribuído para sua dispersão, tornando-o fácil de ser detectado e isolado. De fato, experimentos anteriores mostraram que quando um novo sorotipo é introduzido em uma comunidade, ocorre uma diminuição natural da circulação de outros sorotipos pré-existentes ${ }^{8}$.

Pinheiro e cols ${ }^{9}$ analisaram mosquitos através da RT-PCR e verificaram uma prevalência de $17,1 \%$ para o DENV-3, único sorotipo isolado no estudo. A análise filogenética desse sorotipo mostrou serem pertencentes ao genótipo III, que são representados pelos vírus do sudeste asiático (DENV-3).

Não houve diferença estatisticamente significativa entre os sexos, apesar de em meninos a dengue ter sido mais frequente do que em meninas. No Brasil, vários estudos anteriores demonstraram a incidência de casos de dengue predominantemente na idade adulta $^{10,11}$. Em Manaus, Rocha e Tauil ${ }^{5}$ observaram uma mudança de padrão para a faixa etária infantil, em 2006 e 2007. Eles também observaram que a letalidade de FHD e SCD, em Manaus, nos menores de 15 anos, está acima do aceitável pela OMS (<1\%), apesar de ter havido uma redução de 2006 (12,5\%) para 2007 (4,6\%).

O deslocamento para faixas etárias mais jovens também assinala a gravidade da situação, visto que as crianças são mais suscetíveis ao extravasamento plasmático por apresentarem permeabilidade vascular aumentada ${ }^{4}$. A alta endemicidade e a cocirculação dos três sorotipos no país mostram um importante fator de risco para o desenvolvimento de FHD e SCD por causa da introdução de novos genótipos virulentos. Segundo Gonçalves Neto e $\mathrm{cols}^{12}$, essa mudança de padrão pode ser explicada pelo próprio processo de instalação da endemização da doença, pois a maior incidência da doença em faixas etárias mais elevadas é um padrão observado em áreas indenes logo após a introdução de um novo sorotipo do vírus.

Três (75\%) quartos das amostras positivas para o DENV-3 foram coletadas até o $3^{\circ}$ dia de doença, diferente de estudo realizado na Tailândia ${ }^{13}$, no qual se avaliou o grau de resolução da RT-PCR na dengue secundária em crianças hospitalizadas e o vírus dengue foi mais prevalente em amostras coletadas até o $5^{\circ}$ dia de doença.

Todas as zonas e onze bairros da Cidade de Manaus apresentaram casos positivos nesse estudo. Manaus, como um todo, possui todas as condições ecológicas para o desenvolvimento do mosquito vetor. Fatores ambientais e sociais, tais como alta temperatura e umidade, estações chuvosas prolongadas associadas à pobre infraestrutura, fornecem condições ideais para a proliferação do vetor ${ }^{14}$.

A infecção viral do dengue resulta em uma gama de sintomas que podem ser confundidos com os de muitas outras doenças exantemáticas ${ }^{15}$. No presente estudo, $83 \%$ das crianças analisadas apresentaram resultado negativo para dengue através do RT-PCR sugerindo a ocorrência de outras doenças febris que necessitam ser esclarecidas. Assim, tornam-se necessários estudos mais aprofundados a cerca das arboviroses e outras doenças exantemáticas, cujos sintomas se confundem com o dengue, a fim de se conhecer e estabelecer o real perfil de doenças exantemáticas ocorrentes em Manaus, principalmente no que concerne à atividade viral.

A emergência de casos de FHD e a continuidade de casos reportados de dengue no estado e em todo país, reforçam a importância 
dos métodos laboratoriais para a caracterização da infecção por dengue. A implementação no Brasil do diagnóstico molecular no sistema público poderia ser uma alternativa para tornar rápido o diagnóstico, pois a vigilância virológica e sorológica juntamente com medidas adotadas pelo Programa de Erradicação do Aedes aegypti são as ferramentas mais importantes para alcançar o controle da dengue no país.

\section{AGRADECIMENTOS}

À Fundação de Vigilância em Saúde (FVS) do Estado do Amazonas, ao Laboratório Central de Saúde Pública do Amazonas (LACENAM) e ao Instituto Nacional de Pesquisas da Amazônia (INPA).

\section{CONFLITO DE INTERESSE}

Os autores declaram não haver nenhum tipo de conflito de interesse no desenvolvimento do estudo.

\section{SUPORTE FINANCEIRO}

Fundação de Amparo à Pesquisa do Estado do Amazonas.

\section{REFERÊNCIAS}

1. Gubler JD. Dengue and dengue hemorrhagic fever. Clin Microbiol Rev 1998; 11:480-496.

2. Secretaria de Vigilância em Saúde. Guia de Vigilância Epidemiológica. 6a ed. Brasília: Ministério da Saúde; 2007.

3. Ribeiro AF, Marques GRAM, Voltolini JC, Condino MLF. Associação entre incidência de dengue e variáveis climáticas. Rev Saude Publica 2006; 40:671-676

4. Halstead SB. Dengue in the Americas and Southeast Asia: Do they differ? Rev Panam Salud Publica 2006; 6:407-415

5. Rocha LA, Tauil PL. Dengue em crianças: aspectos clínicos e epidemiológicos, Manaus, Estado do Amazonas, no período de 2006 e 2007. Rev Soc Bras Med Trop 2009; 42:18-22.

6. Lanciotti RS, Calisher CH, Gubler DJ, Chang GJ, Vorndam AV. Rapid detection and typing of dengue viruses from clinical samples by using Reverse TranscriptasePolymerase Chain Reaction. J Clin Microbiol 1992; 30:545-551.

7. Secretaria de Vigilância em Saúde. Informe Epidemiológico da Dengue: janeiro a novembro de 2008. Brasilia: Ministério da Saúde. [acesso dez 2009]. Disponível em http://www.combateadengue.com.br/wp-content/uploads/2009/02/ boletim-janeiro-novembro-2008.pdf/.

8. World Health Organization. Dengue Haemorrhagic Fever: diagnosis, treatment, prevention and control, 2 ${ }^{\mathrm{a}}$ ed. Geneva: WHO; 1997.

9. Pinheiro VCS, Tadei WP, Barros PMSS, Vasconcelos PFC, Cruz ACR. Detection of dengue virus serotype 3 by reverse transcription-polymerase chain rection in Aedes aegypti (Diptera, Culicide), captured in Manaus, Amazonas. Mem Inst Oswaldo Cruz 2005; 100:833-839.

10. Siqueira JB, Martelli CMT, Coelho GE, Simplício ACR, Hatch DL. Dengue and Dengue Hemorrhagic fever, Brasil, 1981-2002. Emerg Infect Dis 2005; 11:48-53.

11. Teixeira MG, Barreto ML, Costa MCN, Ferreira LDA, Vasconcelos PFC. Avaliação de impacto de ações de combate ao Aedes aegypti na cidade de Salvador, Bahia. Rev Bras Epidemiol 2002; 5:108-115.

12. Gonçalves Neto VS, Rebelo JMM. Aspectos epidemiológicos do dengue no município de São Luiz, Maranhão, Brasil, 1997-2002. Cad Saude Publica 2004; 20:1424-1431.
13. As-Ngasang A, Wibulwattanakij S, Chanama S, O-Rapinpatipa A, A-Nuegoonpipat A, Anantapreecha S, et al. Evaluation of PCR as a tool for diagnosis of secondary dengue vírus infection. Jpn J Infec Dis 2003; 56:205-209.

14. Pinheiro VCS, Tadei WP. Frequency, diversity, and productivity study on the Aedes aegypti most preferred containers in the city of Manaus, Amazonas, Brazil. Rev Inst Med Trop Sao Paulo 2002; 44:245-250.

15. Figueiredo RMP, Tatcher BD, Lima ML, Almeida TC, Alecrim WD, Guerra MVF. Doenças exantemáticas e primeira epidemia de dengue ocorrida em Manaus, Amazonas, no período de 1998-1999. Rev Soc Bras Med Trop 2004; 37:476-479. 